\title{
La teología desafiada por un Dios que se hace historia
}

\author{
Sergio Silva \\ PONTIFICIA UNIVERSIDAD CATÓLICA DE CHILE \\ FACULTAD DE TEOLOGÍA
}

Es evidente a simple vista que el tema del título desborda por completo las dimensiones de un artículo. No pretendo, por lo tanto, más que hacer una primera exploración reflexiva. En un primer paso intentaré plantear más precisamente los términos del problema; de ese planteamiento surgirán los dos desafíos a los que voy a dedicar las otras dos partes del trabajo.

\section{Planteamiento}

El punto de partida del planteamiento que presento es la toma de conciencia del carácter histórico de la teología; de él surgen los dos desafíos a que acabo de aludir.

\subsection{El carácter histórico de la teología}

La vinculación de cualquier teología con la historia está ya dada por el solo hecho de que es una obra humana, es decir, que es hecha por seres humanos. Como ha mostrado fehacientemente la filosofía hermenéutica de la segunda mitad del siglo XX, toda obra humana es histórica, en un sentido que tenemos que precisar en un momento más.

Sobre este telón de fondo común a toda obra humana, la teología cristiana tiene un vínculo más poderoso con la historia, en la medida en que su núcleo fundamental es la fe en la Encarnación. Esta fe afirma que el Hijo (o Logos) de Dios, uno de la Trinidad, asumió en Jesús de Nazaret la naturaleza humana y se hizo verdaderamente hombre. Pero el sentido de esta afirmación ha sufrido un cambio importante en la teología actual. En efecto, hasta el comienzo de los tiempos modernos la teología, en 
diálogo con la metafísica clásica, se concentraba en la afirmación de que la encarnación era la asunción, por parte de la segunda persona de la Trinidad, de una auténtica naturaleza humana. En la modernidad se ha ido tomando conciencia de la dimensión histórica del ser humano y, poco a poco, de toda la realidad, y se ha visto cómo todos los seres del universo que conocemos se encuentran en devenir, de modo que no poseen una naturaleza estática, dada por completo y de una vez para siempre. De ahí que en la modernidad la afirmación clásica de que en la encarnación el Hijo-Logos de Dios se hizo hombre haya que explicitarla y ampliarla diciendo que se hizo historia. El punto de partida de la reflexión que aquí propongo es, entonces, la fe en la encarnación, entendida como fe en que el Hijo-Logos de Dios, al hacerse verdaderamente hombre, se ha hecho también verdaderamente historia.

\subsection{Sentido de histórico}

Precisemos algo más el significado de lo histórico. Lo entiendo fundamentalmente como el hecho de que el ser (de todos los entes del universo que conocemos) está en devenir. Ser en devenir implica al menos los siguientes tres rasgos.

a) Estar siendo. Es decir, no ser ya lo que se ha sido en el pasado y no ser aún lo que se va a ser en el futuro. Esto plantea de inmediato una serie de preguntas. ¿Dónde queda lo ya sido? ¿Es mera etapa preparatoria, que se desecha, como se deja de lado la escalera que ha permitido subir al piso superior? ¿Se es finalmente lo último que se ha llegado a ser? Pero en ese caso lo que queda finalmente de todos los entes, incluido el ser humano, es la muerte. En el caso de que lo ya sido se integre en lo que se va siendo, ¿cómo se hace esta integración?

Romano Guardini se ha planteado también este problema, a propósito de la etapa de la juventud. Los movimientos juveniles de Alemania, desde fines del siglo XIX, han descubierto el valor que tiene esta etapa en sí misma, de manera que no vale solo en cuanto etapa que prepara para la adultez. Desde su particular óptica, que sabe descubrir los contrastes que se dan en la realidad, Guardini señala que toda etapa de la vida presenta dos caras. Por un lado, es fase de la única vida, «es decir, procede de la que le antecede y desemboca en la que le sigue. Mas: así como es la meta del tiempo anterior, tiene su meta en el tiempo que le sigue, y el sentido de todas las partes de la vida está en la totalidad». 
Por otro lado, sin embargo, «cada fase tiene también su propio valor y se asienta en sí misma. Porque en cada una está contenida la vida como un todo, cada una es verdadera vida contenida en sí misma, solo que la vida no se agota totalmente en ella». Y concluye: «Este peculiar contraste es parte constitutiva de la vida: que cada fase está referida al todo y, a la vez, sin embargo, se asienta en sí misma; que el ser humano pleno solo se realiza en el conjunto de su vida, pero sin embargo cada instante contiene a un ser humano entero» ${ }^{1}$.

La Escritura permite asegurar que lo ya sido no se pierde en la muerte. Lo intuía ya el salmista cuando se dirigía a Dios pidiéndole: «Anota en tu Libro los pasos de mi vida errante, recoge mis lágrimas en tu Odre, Dios mío» (Sal 56, 9). Y lo anuncia el hecho de que Jesús ha resucitado; más aun, como en su cuerpo han quedado incorporadas las huellas de su muerte, ni siquiera esta se desvanece en la nada, sino que de una manera misteriosa que apenas podemos imaginar queda incorporada en el mundo de Dios.

b) Estar siendo en relación con el entorno. Los entes del universo se presentan jerarquizados en niveles diversos de ser, de menos a más plenitud (materia inorgánica, vida vegetal y animal, vida síquica, vida espiritual humana ${ }^{2}$, y están todos relacionados, porque todos comparten la misma materia, que se va integrando en los niveles superiores, «D.h. es geht aus dem voraufgehenden hervor und mündet in das folgende ein. Mehr: Wie es selbst das Ziel des vorausgehenden Zeit ist, so hat es sein Ziel in der nachkommenden, und der Sinn für alle Teile des Lebens liegt im Ganzen». «Jede Phase hat auch ihren Eigenwert und steht in sich. Denn in jeder ist das Leben als ein Ganzes enthalten, jede ist wirkliche in sich geschlossene Lebendigkeit - nur geht das Leben nicht ganz in ihr auf». «Diese eigentümliche Gegensätzlichkeit macht mit das Problem des Lebens aus: Dass jede Phase auf das Ganze bezogen ist und doch zugleich in sich steht; dass der volle Mensch sich nur im Gesamten des Lebens verwirklicht, aber doch jeder Augenblick einen ganzen Menschen enthält». R. GUARDINI, «Die Sendung der katholischen Jugend» en Wurzeln eines grossen Lebenswerks. Aufsätz̨e und Kleine Schriften, Band II, Mainz, Mathias Grünewald y Paderborn, Ferdinad Schöningh, 2001) 7-22; todas las citas, 11. Esta cita de Guardini y otras que siguen no pretenden sino apoyar o ampliar lo que he afirmado en este artículo. La traducción de esta cita y de las que siguen es mía.

2 Esta idea se encuentra a menudo en los escritos de Guardini; por ejemplo, en «Sagrada Escritura y ciencia de la fe», en R. GuARDini y otros, Biblia y ciencia de la fe. Edición, traducción e introducción de Carlos Granados y Agustín Giménez. (Madrid 2007) 17-66; ver 19. Original: «Heilige Schrift und Glaubenswissenschaft» [1928], en R. 
y los de nivel superior necesitan de los entes de los niveles inferiores. En este entorno, por lo tanto, cada ente se encuentra con otros entes que le son semejantes en diverso grado, a la vez que le son diferentes en diverso grado; y se relaciona de manera diversificada con ellos, en un trato de dar y recibir (que no solo es siempre y necesariamente positivo, sino que puede ser también destructivo).

En el caso del ser humano podemos hablar de interacción cuando se trata de las relaciones que entabla con los otros seres humanos de su entorno; sean los que puede encontrar cara a cara (sus contemporáneos), sean los que encuentra mediante sus obras (la cultura que recibe de los antepasados). Importantes corrientes de la filosofía contemporánea $-\mathrm{y}$, en diálogo con ellas, también de la teología- se han hecho cargo de este carácter relacional del devenir del ser humano; lo han hecho a menudo bajo el concepto de alteridad; pero no siempre han tenido en cuenta que el otro puede ser también dañino, destructor.

Todos los entes del universo participan de estos dos rasgos del devenir. En el caso del ser humano se añade un tercero:

c) Ser en devenir desde un centro interior de conciencia y libertad, capaz de decidir (lo que la Sagrada Escritura llama el corazón humano). Esto hace que el ser humano pueda y deba tomar su vida en sus propias manos, hacer un proyecto de su propio ser, intentar llevarlo a una determinada meta que él se plantea libremente; es decir, el devenir del ser humano está orientado, atraído por un porvenir. Este proyecto de porvenir puede tener éxito o fracasar (con toda la gama intermedia), puede ir también en contra de lo que se es por naturaleza (como en el caso tan patente de la drogadicción o de la opresión, y tantos otros), lo que plantea la pregunta por los criterios para la gestación del propio proyecto de ser y su relación con la naturaleza ya dada. Aquí también surgen las preguntas de fondo sobre la existencia de dicha naturaleza humana, el puesto que en ella ocupa el devenir histórico y cómo accedemos nosotros, desde la historia, al conocimiento de esta naturaleza.

GUARDINI, Wurzeln eines grossen Lebenswerks. Aufsätze und kleine Schriften, Band II, 337383. Mainz, Mathias Grünewald y Paderborn, Ferdinad Schöningh, (2001); ver 339. 
Me parece oportuno hacer dos observaciones respecto de la historicidad así entendida. La primera es que los tres rasgos que he señalado en el ser histórico muestran la fragilidad de todos los entes que devienen en la historia. El devenir los lleva, antes o después, inevitablemente a la muerte, a la disolución. Las relaciones con su entorno no necesariamente están al servicio de su desarrollo, sino que pueden dificultárselo, incluso impedírselo radicalmente. El proyecto humano de porvenir puede fracasar. Esta fragilidad es, probablemente lo que la Escritura, sobre todo la del Antiguo Testamento, ha expresado con el término carne. Una punzante expresión de esta fragilidad la encontramos en Is 40, 6-8; curiosamente, en el contexto de la misión que recibe el profeta de consolar al pueblo exiliado: «Una voz dice: "Grita!” Y digo: "¿Qué be de gritar?" - "Toda carne es hierba y todo su esplendor como flor del campo. La flor se marchita, se seca la bierba, en cuanto le dé el viento de Yavé. La bierba se seca, la flor se marchita, mas la palabra de nuestro Dios permanece por siempre"》. Sin embargo, el término carne ha quedado incorporado, gracias a Jn 1, 14, en el de encarnación, con el que nos referimos al hecho central de nuestra fe cristiana. Así, la encarnación del Hijo-Logos de Dios, entendida como hacerse hombre histórico con los tres rasgos recién señalados, hace que este Hijo-Logos comparta la enorme fragilidad fundamental del ser humano.

La segunda observación es que el estar-siendo-en-relación-con-otrosen-dirección-a-un-porvenir no se limita solo al ser de un ente individual, sino que se extiende a toda la trama de los entes a lo largo del tiempo. Porque todo ente individual, de cualquiera de los cuatro niveles jerárquicos de ser que sea, proviene de otros entes individuales y afecta a otros e influye sobre ellos. Por eso, en el nivel del ser propiamente humano, la Encarnación no se puede comprender aislada de la historia de Israel, que la hizo posible, ni de la historia de las comunidades cristianas a las que dio origen. $\mathrm{Y}$ en los otros tres niveles, que también son asumidos al encarnarse el Hijo-Logos, la Encarnación no puede ser separada de la naturaleza ni, por lo tanto, en la perspectiva teológicamente, de la creación.

\subsection{Dos desafíos mayores}

Si cabe usar para la teología la analogía de la interpretación musical, podemos decir, entonces, que la teología es histórica no solo ni principalmente porque su intérprete -el teólogo- lo es, sino porque, decisivamente y ante todo, su tema es histórico, por cuanto se trata de pensar al Dios que se encarna y, así, se hace historia. 
Esto plantea a la teología al menos dos desafíos, que son los que me propongo reflexionar en lo que sigue:

a) ¿Qué hace posible en Dios y en la historia humana que Dios se haga historia, es decir, que pueda devenir-en-interacción-con-los-demás-endirección-a-un-porvenir?

b) ¿Cómo ha de ser la teología que piense adecuadamente este hacerse historia de Dios y cómo ha de ser el lenguaje en que se exprese esa teología?

\section{Condiciones de posibilidad de que Dios se haga historia}

Las condiciones que hacen posible que Dios se haga historia las tenemos que buscar tanto en Dios como en la historia.

\subsection{En Dios}

Al buscar en Dios las condiciones que le hacen posible hacerse historia, estamos aventurándonos en un territorio que nos supera infinitamente. Tenemos que recordar, con Tomás, que «del mismo Dios más se nos manifiesta lo que no es que lo que es» ${ }^{3}$. Sin embargo, por lo que Jesús nos ha dado a conocer del Padre y, por ello, de la intimidad de Dios, podemos balbucear un intento de comprensión.

La condición básica que hace posible que Dios se haga historia, es decir, que pueda devenir-en-interacción-con-otros-en-dirección-a-un-porvenir, es el hecho de que Dios es Trino. El carácter trinitario de Dios no consiste en primer lugar en su rasgo triádico, es decir, en que las Personas en Dios son numéricamente tres. Consiste, más bien y ante todo, en el hecho de que Dios, el Padre, está desde siempre y para siempre dándose en el interior de sí mismo, engendrando así al Hijo y, con él, espirando al Espíritu.

La sustancia de Dios -si es que podemos hablar en estos términos- es por lo tanto el Amor que se da, que se autocomunica, que sale fuera de sí en un movimiento de extroversión, que engendra, en su propio interior,

\footnotetext{
Magis enim manifestatur nobis de ipso [Deo] quid non est, quam quid est, S.Th. 1a, 1, 9, ad 3. Poco antes había dicho: (...) licet de Deo non possimus scire quid est, (aunque de Dios no podamos saber qué es) (S.Th. 1a 1, 7, ad 1.).
} 
vida nueva ${ }^{4}$. Este movimiento interior de Dios lo podemos llamar -de nuevo balbuceando lo innominable- un movimiento de Supra-Devenir. Como este movimiento de amor produce en sí la diversidad de hipóstasis o personas, se trata de un movimiento relacional, de modo que podemos -de nuevo balbuceando- decir que este Supra-Devenir de Dios es un Supra-Devenir-con-Otros. Y como el amor de Dios ha querido derramarse también sobre otros, saliendo fuera de su propia intimidad, ha hecho suyo un futuro, que podemos llamar un Supra-Porvenir, ese que Pablo describe con la expresión «Dios todo en todos» $(1$ Co 15,28$)$

Quizá no hemos sacado ni en teología ni en filosofía todo el partido posible de la audacia de Tomás al definir las hipóstasis divinas como relaciones subsistentes ${ }^{5}$, lo que es, a primera vista, una contradicción, porque lo que subsiste es la sustancia, mientras que la relación es accidente. Si el ser humano ha sido creado a imagen y semejanza de Dios, algo de este carácter de ser relación subsistente deberá encontrarse también en él. En los desarrollos de la filosofía personalista del siglo XX y en ciertas corrientes de la sicología se ha acentuado que el ser humano se descubre a sí mismo solo en relación con los otros significativos que encuentra en su entorno, especialmente en su primera infancia; pero queda abierto a la influencia de los demás hasta el fin de su vida. Quizá, en la línea de Tomás, habría que dar un paso más y afirmar que el ser humano no solo se descubre sino que llega a ser lo que es en esa relación con los otros. De modo que más que un sujeto (en cierto modo ya constituido) que entra en relación con otros sujetos como él y en esa relación crece y se descubre a sí mismo, habría que decir que el ser humano se hace sujeto en la relación con los demás, incluida aquí, y decisivamente, su relación con Dios. Me parece en este sentido muy acertada la siguiente afirmación de Romano Guardini: «El hombre no está acabado en sí mismo y, además, llamado a ir a Dios,

4 Hans Urs von Balthasar ha subrayado el movimiento que él llama de Ur-kenose (kénosis primordial, originaria) en Dios por el cual el Padre se despoja de sí para engendrar al Hijo. De ella surgen la creación, la alianza y la encarnación, que culmina en la cruz y la eucaristía; ver Theodramatik III, párrafo «Schöpfung, Bund, KreuzEucharistie». Hans Urs von Balthasar, Theodramatik. Dritter Band: Die Handlung. Einsiedeln, Johannes Verlag, 1980, 305-309 .

5 Personae [divinae] sunt ipsae relationes subsistentes (Las Personas divinas son las relaciones subsistentes mismas) (S.Th. $1^{\mathrm{a}}$, 40, 2, ad 1.). (...) relatio supponit distinctionem suppositorum, quando est accidens; sed si relatio sit subsistens, non praesupponit (la relación supone una distinción respecto de los supuestos cuando es accidente; pero si la relación fuese subsistente, no la presupone) (S.Th. 1 ${ }^{\mathrm{a}}, 40,2$, ad 4.). 
sino que, solo cuando se dirige a Dios, encuentra ante Él su auténtica identidad y la paz de la verdad» ${ }^{6}$.

Podemos concluir que, si Dios, en su propia intimidad, Deviene-conOtros que son las hipóstasis divinas, entonces puede, en la encarnación, hacerse historia y devenir-con-otros que son los seres humanos. La libertad de ambos movimientos de devenir -el intradivino y el que se da fuera de Dios, en nuestra historia- está asegurada porque se trata de un devenir que surge del amor que es Dios, que no necesita nada para sí sino que quiere compartir con otros su gozo de amar.

\subsection{En la historia}

Preguntémonos ahora si hay en la historia algo que haga posible la encarnación, entendida como el hacerse historia del Hijo de Dios.

A esta pregunta se han dado dos respuestas extremas que son inadecuadas. La de Hegel (y, en alguna medida, también de los panteísmos), que parece afirmar que la historia produce (o secreta) la encarnación, en la medida en que el Espíritu absoluto, para hacerse Espíritu subjetivo y poseerse en plenitud a sí mismo, debe hacerse Espíritu objetivo, es decir, debe salir de sí y hacerse mundo e historia, para culminar su proceso de autoposesión en el ser humano. En esta perspectiva se pierde la libertad de Dios, pues no cabe un Absoluto libre, un Logos ya establecido con poder, que se den a conocer libremente al ser humano; por el contrario, como muestra Salmann: «Más bien es el Absoluto el que se piensa a sí mismo en la reflexión de la humanidad; el Logos es engendrado en la historia de reflexión del Espíritu. La historia de la reflexión del ser humano sobre sí mismo y de la fundamentación de la historia se convierte en paso necesario del Absoluto mismo» ${ }^{7}$. La otra respuesta extrema es la de Barth,

6 Er [der Mensch] ist nicht in sich selbst fertig und ausserdem gerufen, zu Gott zu gehen, sondern erst wenn er zu Gott hinübergeht, findet er vor Ihm sein eigentliches Selbst und den Frieden der Wahrheit, R. Guardini, «Anfang. Eine Auslegung der ersten fünf Kapitel von Augustins Beknntnissen», en R. GuARDINI, Wurzeln eines grossen Lebenswerks. Aufsätze und kleine Schriften, Band 3. Mainz, Grünewald y Paderborn, Schöningh, 2002 (original de 1944), 258-259. Traducción castellana: La cuestión judía. Principio: una interpretación de San Agustín. (Buenos Aires, Sur, 1963).

«Vielmehr denkt das Absolute sich selbst in der Reflexion des Menschen, es wird der Logos erst aus der Reflexionsgeschichte des Pneuma herausgeboren. Die Geschichte menschlicher Selbstreflexion und Geschichtsbegründung wird zum notwendigen Gang des Absoluten selbst», E. Salmann, «Offenbarung und Neuzeit. Christologische 
que parece negar que Dios pueda entrar realmente en el mundo, pues habla -ya que no puede negar la encarnación si quiere ser cristiano- de un encuentro meramente tangencial de Dios y lo humano en la historia.

Para plantear más detenidamente el problema me parece esclarecedor tomar conciencia de dos aspectos fundamentales de la realidad del mundo y de la historia. Al primero ya he hecho alusión al inicio: es el hecho de que el mundo se nos presenta -podríamos decir, en un corte estáticocomo un conjunto de entes diversos, pero organizado según un orden jerárquico de ser, desde el nivel inferior de la materia inorgánica, pasando por los niveles de la vida vegetal y animal y de la vida síquica, hasta llegar al nivel superior del ser humano dotado de espíritu. Hay que advertir que no se trata de capas de ser simplemente yuxtapuestas, sino que los niveles superiores integran en sí los inferiores; así, el ser humano es un microcosmos en el que encontramos todos los niveles del ser.

El segundo aspecto es dinámico. De él se ha empezado a tomar conciencia recién en la segunda mitad del siglo XIX. Este mundo con sus niveles jerárquicos de ser ha evolucionado en el tiempo, desde la pura materia inorgánica hasta el ser humano. (Lo que plantea, dicho sea de paso, el problema de saber si los diversos niveles de la vida, vegetal, animal y síquica, y el mismo ser humano espiritual, son meros epifenómenos de la materia, solo que en una organización cada vez más compleja, pero sin especificidad propia).

Sobre este telón de fondo, Dios puede ser pensado como un quinto nivel, ahora sí supremo e insuperable, en la jerarquía del ser; la pregunta es, entonces, cómo puede Dios, desde fuera del ser del mundo (porque rechazamos los panteísmos), entrar verdaderamente en él y hacerse historia (porque rechazamos la tangencialidad que Barth atribuye a la irrupción de la revelación de Dios en la historia).

Los teólogos católicos se mueven, según su sensibilidad, más cerca de un polo o de otro. A mi juicio, para nombrar a dos grandes del siglo XX, Balthasar está más cerca de afirmar una irrupción de Dios en una historia que no presenta de suyo condiciones para recibirlo -es Dios mismo quien las crea-, mientras que Rahner subraya lo que ya hay en el mundo -pero por creación de Dios- como condición que hace posible que Dios se haga

Überlegungen zur geschichtlichen Situation» en Freiburger Zeitschrift für Philosophie und Theologie 31 (1984) 109-154; la cita es de la 149. La traducción en el texto es mía. 
historia (los temas de la trascendencia y el existencial sobrenatural van en esta dirección).

Me siento más cerca de Rahner. Me parece que sus ideas teologizan adecuadamente las afirmaciones fundamentales del Nuevo Testamento sobre el papel de Cristo, del Logos encarnado, en la creación, que ha sido «hecha en él (...), por él y para él» (Col 1, 16; ver Jn 1, 3), y que está destinada a ser recapitulada en él (Ef 1,10).

Además, en la perspectiva de Rahner se hace justicia, a mi entender, a una experiencia mística fundamental, que consiste en que a Dios no lo podríamos buscar, si de alguna manera ya no lo tuviéramos. De nuevo me parece justa una afirmación de Guardini: «la verdadera búsqueda está orientada por una imagen, aunque esta no tenga sino la forma de una ausencia y una necesidad. Solo se puede buscar de verdad aquello que el deseo anticipa; por ello, el hallar de verdad es, en lo profundo, un tomar posesión; por ello, también, en el momento del auténtico encuentro se tiene el sentimiento de que así tenía que ser"». En la poesía mística encontramos a menudo esta misma idea. Para poner un ejemplo, en la estrofa 12 del Cántico Espiritual (redacción definitiva) dice Juan de la Cruz: « $\mathrm{O}$ Oh cristalina fuente, / si en esos tus semblantes plateados / formases de repente / los ojos deseados / que tengo en mis entrañas dibujados!» También en la poesía amatoria hay algo de esto, que se puede fácilmente trasponer al registro del amor de Dios. De nuevo, un ejemplo, tomado esta vez de Pedro Prado: «Sin saber yo de ti, tú ya eras mía; / al encontrarte, en ti reconociera / algo perdido que, en la tierra entera, / sin saber lo que fuese, perseguía»?

\section{Exigencias para una teología que se haga cargo de que Dios se ha hecho historia}

$\mathrm{Al}$ reflexionar sobre la exigencia para la teología de hacerse cargo de que Dios se ha hecho historia, podemos distinguir, aun sabiendo que no se pueden separar, dos aspectos: el pensar teológico y el lenguaje en que ese pensamiento se expresa.

8 (...) wirkliches Suchen ist voon einem Bilde gelenkt und habe es auch nur die Form des Fehlens und Bedürfens. Wirklich suchen kann man nur, was das Verlangen schon vorwegnimmt, sodass wirkliches Finden zutiefst ein In-Besitz-Nehmen ist, daher sich denn auch im Saugenbilck der echten Begegnung das Gefühl einstellt, so habe es kommen müssen, R Guardini, o.c., 260.

9 P. PRADO, Otoño en las Dunas. (Santiago 1940) Soneto XII, primera cuarteta. 


\subsection{Exigencias para el pensar teológico}

Voy a señalar tres exigencias que debe satisfacer el pensar teológico si quiere hacerse cargo de que Dios se ha hecho historia, que me parecen particularmente significativas hoy.

a) En la creación -y, por lo tanto, en el ser humano y en la historia- hay un anhelo de Dios, puesto por Él mismo en el acto creador; Dios es el porvenir al que aspira, aun sin saberlo, el devenir de los entes. Entonces la teología no puede evitar una circularidad de tipo hermenéutico. No me refiero a la circularidad afirmada ya por Anselmo, pero presente desde el inicio de la reflexión cristiana, al definir la teología como fides queaerens intellectum (fe que busca comprensión). En esta circularidad anselmiana es la fe explícitamente afirmada la que mueve al teólogo a buscar comprenderla. La circularidad a la que me quiero referir aquí es una circularidad más básica, porque no se trata de explorar la fe sino ese sustrato suyo dado en la historia, que acabamos de afirmar; es el círculo entre el Dios ya poseído de alguna manera no siempre explícita ni correctamente expresada, el Dios al que apunta la trascendencia del ser humano, su anhelo más profundo -el deseo natural de ver a Dios al que apunta Tomás ${ }^{10}-$, y el Dios revelado en Jesucristo; es el círculo entre el Dios al que se aspira desde dentro de la historia y el Dios que le llega desde fuera.

De esta consideración surge una primera condición o requisito del pensar teológico. Su interlocutor han de ser los contemporáneos. De otro modo, el teólogo corre el riesgo de hacer una teología fuera de la historia, irrelevante; porque es en la historia actual donde se sigue dando Dios. Aquí encuentra su lugar el tema de los signos de los tiempos, que debería ser acometido con ímpetu por la teología.

\footnotetext{
La expresión no se encuentra tal cual en los escritos de Tomás indexados en el Index Thomisticus. Pero el contenido sí. Por ejemplo, Contra Gentes, parte $3^{a}$, cap. 25, n. 12: «nadie alcanza su último fin mientras no se aquieta su deseo. Por lo tanto, a la felicidad humana, que el el fin último, no le basta cualquier conocimiento intelectual, si no cuenta con el conocimiento de Dios, que pone término, como fin último, al deseo natural». O bien en el mismo Contra Gentes parte $3^{\text {a }}$, cap. 51, n. 1: «Como es imposible que un deseo natural sea vano, y lo sería si no fuera posible llegar a entender la sustancia divina, que es lo que todas las mentes desean naturalmente, es necesario decir que es posible, tanto a las sustancias separadas como a nosotros, ver la sustancia de Dios mediante el entendimiento».
} 
b) Un segundo requisito que debe cumplir una teología que acepte el desafío de la historia ha quedado ya insinuado en lo anterior, cuando me refería al círculo hermenéutico involucrado en la definición de la teología cristiana de Anselmo. La fe que se trata de pensar en la teología, nuestra fe, es la fe apostólica. Es decir, se trata de pensar hoy al Dios del que da testimonio la Biblia, al Dios que ya se ha hecho historia. Se trata de pensarlo en diálogo con la filosofía, pero sin reemplazar al Dios de Jesucristo por el Dios de los filósofos y de los sabios (como decía Pascal). Una y otra vez el teólogo tiene que repetir la palabra de Rut, la moabita, a su suegra Noemí: «Tu Dios será mi Dios», dirigiéndola a Jesús. Por eso, el alma de la teología ha de ser siempre la Escritura.

Esto, sin embargo, plantea un problema mayor, que es el de la interpretación de la Escritura, habida cuenta del creciente «conflicto de interpretaciones» que se da actualmente. Para ilustrar el problema me detengo un momento en el documento de la Pontificia Comisión Bíblica titulado La interpretación de la Biblia en la Iglesia, de 1993. Ahí se afirma la legitimidad de una serie de métodos de análisis del texto bíblico, definidos como «un conjunto de procedimientos científicos puestos en acción para explicar los textos» y de varios acercamientos, definidos como «una búsqueda orientada según un punto de vista particular» ${ }^{11}$. Me parece muy sana la apertura a la pluralidad de métodos y acercamientos, porque el texto bíblico supera con mucho lo que cada método o acercamiento puede captar de él. Sin embargo, la pura apertura a lo plural me parece que no basta. El teólogo necesita un criterio de discernimiento que le permita acercarse a lo fundamental de las afirmaciones de la Escritura. El Documento de la Pontificia Comisión Bíblica da dos indicaciones en esta dirección. La primera es que el método histórico-crítico sigue teniendo la prioridad, porque es el que permite descubrir el sentido del texto en el ayer en que el autor lo escribió. La segunda es que la exégesis, que trabaja con este método, debe ser complementada con una hermenéutica, que traslade su sentido del ayer del texto al hoy de la vida de fe de la Iglesia. No me parece correcta esta división del trabajo entre exégesis histórico-crítica y hermenéutica, porque no hay exégesis (con cualquier método que trabaje) que no sea al mismo

${ }^{11}$ La Interpretación de la Biblia en la Iglesia. Discurso de su Santidad el Papa Juan Pablo II y Documento de la Pontificia Comisión Bíblica (Santiago 1994), ambas citas en 31. 
tiempo hermenéutica, debido a que el exégeta no puede desprenderse del horizonte histórico que lo ha formado y en el que vive, para trasladarse -en cierto sentido convertido en una especie de yo puro, ahistórico- al horizonte en que se escribió el texto bíblico. Por eso, pienso que si la teología quiere hacer de la Escritura su alma, debe tomar la perspectiva hermenéutica como su englobante último y, en su interior, podrá (y deberá) dar cabida a los muchos procedimientos científicos contemporáneos que ayudan a explicar el texto, como un aporte a su comprensión; entre ellos, también al método histórico-crítico.

c) A los dos requisitos ya señalados quiero añadir una tercera exigencia, quizá menos evidente. El modo de pensar de la teología no debe ser uno que busque fjar naturalezas estáticas, sino mostrar estructuras del devenir. Lo fundamental, si Dios se ha hecho (y se sigue haciendo) historia, es el devenir. Pero no un devenir amorfo, caprichoso, sino estructurado.

Ejemplos de modos de pensar el devenir con estructura me parece que son, en el plano del análisis de los relatos, la Semántica estructural de A.J. Greimas ${ }^{12}$; en el plano de la filosofía del ser vivo, la filosofía del contraste (Gegensatz) de Guardini ${ }^{13}$.

Este modo de pensar busca el concepto no como un término definitivo sino como baranda que apoya en el cauce del devenir, impidiendo la caída. Reconoce que el concepto nunca agota lo real, menos aun la realidad del Dios que se hace historia.

Quizá el concepto corresponde a la inteligencia lógica (que alcanza su desarrollo hacia los 18 años y su plenitud hacia los 30), mientras que la inteligencia adecuada a la teología sea la sapiencial, la inteligencia de los contrarios (que culmina hacia los 50 años y puede mantenerse viva hasta mucho más allá de los 80 ). Vale la pena escuchar al siquiatra Ricardo Capponi: «Hay una inteligencia fluida y una inteligencia cristalizada. La primera tiene que ver con la rapidez para solucionar problemas, la que se empeora a partir de los 25 años. La segunda tiene que ver con la capacidad de determinar lo esencial, la que se va mejorando

12 A.J. Greimas, Sémantique structurale. Recherche de méthode (Paris 1969).

13 R. Guardini, Der Gegensatz: Versuch zu einer Philosophie des lebendig Konkereten [Mainz ${ }^{2} 1955$ (1925)]. 
con los años». Y añade: «Es importante lograr un pensamiento formal, reflexivo, capaz de abstracción. Del mismo modo, un pensamiento posformal, a través del cual las cosas se relativizan, se establece una relación dialéctica entre ellas, obteniendo una visión global, sintética. Esto último se consigue, en su punto máximo, a los 50 años, y después se mantiene» ${ }^{14}$.

Hay aquí tarea de largo plazo para la teología. Un camino que parece prometedor está empezando a abrirse en los estudios que emplean los métodos literarios narrativos para la interpretación de la Escritura y en la proyección teológica de la idea de narratividad. No en vano afirmamos que Dios se nos ha comunicado y entregado en una historia de salvación.

\subsection{Exigencias para el lenguaje teológico}

El lenguaje teológico nunca podrá ser un lenguaje directo, que describa o denote a Dios, porque «a Dios nadie lo ha visto nunca» (Jn 1, 18); tendrá, por ello, que ser necesariamente un lenguaje indirecto, que connote a Dios a partir de nuestras experiencias en el mundo. Denotar y connotar son expresiones técnicas de algunos lingüistas del siglo XX, como por ejemplo Roland Barthes ${ }^{15}$. Voy a presentar dos aproximaciones a este lenguaje indirecto. Una es lo que yo descubro en un estudio acerca del lenguaje de Jesús en los evangelios. La otra es una propuesta de Guardini.

a) Más que atender al contenido de la enseñanza de Jesús, me parece importante para nuestro propósito fijarnos en la forma literaria en que se presenta, porque es ella la que debe adecuarse al contenido fundamental que, en el caso de los sinópticos, es el Reinado de Dios y, en Juan, la Vida. Me parece haber descubierto cuatro características principales en la forma de la enseñanza de Jesús ${ }^{16}$.

Presentadas en el orden de mayor a menor frecuencia, la primera es el uso de la contraposición (detecto 135 casos). Se trata de expresiones de Jesús en que hay una oposición, por ejemplo, entre la carne, «que

14 Texto, entregado por el autor, de una conferencia en el encuentro de religiosos de los Sagrados Corazones de la tercera edad, 26 de septiembre de 2007.

15 R. Barthes, Éléments de Sémiologie. Traducción castellana: Elementos de Semiología (Madrid 1970).

16 S. Silva, ¿Por qué murió Jesús? Iniciación a los Evangelios. Volumen I: Lectura del Drama (Santiago 1996) capítulo 11, especialmente 328-346. 
no sirve para nada», y el Espíritu, «que da vida» (Jn 6, 63); o entre el mensaje de Jesús, que ahora está oculto, diciéndose al oído, pero que después ha de ser descubierto y proclamado por los Doce en público y en alta voz (Mt 10, 26-27 y pp.). El sentido de esta característica me parece ser el siguiente: «Jesús anuncia la presencia inminente del Reinado de Dios. Para acoger este reinado, la persona debe tomar conciencia lúcida de la radical e insalvable diferencia que hay entre Dios y ella misma; solo así podrá recibir el Reinado de Dios como regalo absolutamente inmerecido; podrá, por lo tanto, asombrarse terriblemente y alegrarse de verdad. Ahora bien, enfrentado a este regalo, el ser humano es libre de aceptarlo o rechazarlo. Por eso, la primera contraposición fundamental, la que hay entre Dios y el ser humano, se refracta en la segunda: los dos caminos que se abren al ser humano enfrentado a la inminente irrupción del Reinado de Dios: el de escucha y salvación, o el de cierre y condenación $\rangle^{17}$.

La segunda característica es el uso de la metáfora y de la comparación (detecto 96 casos); la comparación puede aparecer en distintos grados de explicitación. «Vale la pena que nos preguntemos qué dicen la metáfora y la comparación acerca del contenido de esta enseñanza. A mi juicio, nos dicen que lo que Jesús nos quiere comunicar -el Evangelio de la inminente llegada del Reinado de Dios- podemos entenderlo gracias a nuestra experiencia con los términos de la comparación; pero, al mismo tiempo, nos advierten que esa comunicación de Jesús no es todavía captable directamente en sí misma. Porque toda comparación dice, por un lado, que lo comparado se parece a aquello con lo que se lo compara; pero, por otro, nos deja con la insatisfacción de no poder decirlo por sí mismo: su diferencia se nos escapa. Dicho de otra manera, el Reinado de Dios que Jesús anuncia cabe en nuestra experiencia humana, está emparentado con ella; pero no coincide exactamente con lo que hasta ahora ha sido esa experiencia nuestra ${ }^{18}$.

La tercera característica es el uso de la exageración (encuentro $40 \mathrm{ca}-$ sos). Se trata de expresiones como colar el mosquito y tragar el camello (Mt 23, 24), ponerse al cuello una piedra de molino y arrojarse al mar (Mt 18, 6), cortarse la mano o arrancarse el ojo si son ocasión de pecado (Mt 5, 29-30 y pp.), etc. «Se suele afirmar que la exageración

17 S. SiLva, ¿Por qué murió Jesús? 340.

18 S. SiLva, ¿Por qué murió Jesús? 333. 
es un rasgo típico del pueblo de Israel en tiempos de Jesús. Que Jesús emplee formas exageradas de expresión no sería, pues, más que un nuevo tributo pagado por el Logos de Dios a su Encarnación. A lo sumo, sería otro aspecto del esfuerzo del Hijo de Dios por hacerse uno de nosotros en todo, menos en el pecado. Esa explicación, siendo verdadera, se queda sin embargo en la superficie de las cosas. Si Jesús ha recurrido a estas expresiones exageradas es porque con ellas algo quiere transmitir. A mi juicio, se trata de una expresión adecuada de la realidad profunda que Jesús anuncia. Que Dios ame al hombre con esa intensidad que se ha manifestado en Jesús y que lo invite a entrar en plena comunión con Él, eso solo se puede expresar adecuadamente reventando con la exageración nuestras expresiones habituales. Porque se trata del anuncio de algo de suyo imposible, que solo Dios puede realizar. Es algo imposible no solo por el pecado nuestro, sino también y ante todo porque somos creaturas limitadas, finitas, que hemos de recibir en nosotros la plenitud del Creador ilimitado, infinito. ¿Cómo decir lo imposible e impensable de otro modo que con expresiones que se salen de lo posible y revientan los moldes de lo pensable?» ${ }^{19}$.

Finalmente, en las palabras de Jesús encontramos el uso de algo que, a falta de mejor expresión, he llamado inclusión (está en 20 lugares). Se trata de expresiones en que Jesús, «sus discípulos y el Padre aparecen en una relación de cierta proporcionalidad, como si los discípulos estuvieran incluidos en Jesús y Este en su Padre, de modo que la actitud ante uno es la actitud ante el otro» ${ }^{20}$. «Pienso que el sentido de estas inclusiones es dar expresión a lo que constituye el centro del mensaje de Jesús, porque es a la vez el núcleo de su propio ser: Dios en el hombre, Dios-con-nosotros, la Alianza definitiva de Dios con la humanidad, hecha en su carne y sangre humanas» ${ }^{21}$.

Vemos, pues, que el lenguaje de Jesús sobre Dios y su Reinado es indirecto. Esto lo confirma el abundante empleo de parábolas (cuento 54) ${ }^{22}$, que son metáforas o comparaciones en que uno de los términos -el que es tomado de la realidad humana cotidiana para trasladarlo luego al mundo de Dios- se desarrolla hasta convertirse en un relato, más o menos porme-

\footnotetext{
19 S. Silva, ¿Por qué murió Jesús? 344.

20 S. SILVA, ¿Por qué murió Jesús? 344-345.

21 S. SiLva, ¿Por qué murió Jesús? 346.

22 S. SiLva, ¿Por qué murió Jesús? capítulo 12, 363-392.
} 
norizado. El sentido último de por qué Jesús usa metáforas y parábolas me parece que lo expresa el evangelista Juan en uno de los diálogos de Jesús con los discípulos en la última cena. «Cerrando ya la larga conversación que han tenido, y poco antes de hacer su oración final al Padre, les dice Jesús a los suyos: Les he dicho todo esto en "parábolas"'. Se acerca la hora en que ya no les hablaré en parábolas, sino que "con toda claridad"24 les anunciaré al Padre (Jn 16, 25). Le dicen los discipulos: "Ahora sí que hablas con toda claridad y no dices parábolas. Sabemos ahora que lo sabes todo y no necesitas que nadie te interrogue. Por esto creemos que has venido de Dios". Jesús les respondió: "¿Ahora creen? Miren que llega la hora -y ya ha llegado - en que se dispersará cada uno de ustedes por su lado y me dejarán solo. Pero no estoy solo, porque el Padre está conmigo" (Jn 16, 29-32). La hora a la que se refiere Jesús es la hora de su elevación, de su muerte en la cruz y de su retorno al Padre. Es cuando está en la cruz que Jesús ya no necesita hablar del Padre y de su Reinado empleando parábolas: puede dejar hablar a su cuerpo que se entrega, a su sangre que se derrama, a su persona que se devuelve confiadamente al Padre, de quien se sabe recibido: Salí del Padre y vine al mundo, ahora dejo el mundo y voy al Padre (Jn 16, 28)» $\aleph^{25}$.

b) Guardini contrapone la afirmación directa y la indirecta ${ }^{26}$. La primera explica las características de un ser -su magnitud, su color-, pone nombre a su esencia, da a conocer el orden que lo constituye; se trata, así, de una expresión acabada, cabal. La podemos asimilar a lo que, como hemos recordado, algunos lingüistas llaman la capacidad de denotación, la capacidad del lenguaje de describir con exactitud el mundo observable.

Pero hay objetos, afirma Guardini, que no se pueden asir mediante este tipo de afirmaciones, porque no se identifican con ninguna afirmación simple, ya que estas solo pueden dar forma abstracta a algo particular: propiedades, actos, relaciones. Estos objetos presentan un carácter de totalidad, de lo viviente concreto, por lo que no se los puede pensar

23 El texto griego -aquí y en los otros dos lugares en que traduzco parábola- no usa $\pi \alpha \rho \alpha \beta \jmath \lambda \eta ் ~(p a r a b o l e ́) ~ s i n o ~ \pi \alpha \rho o \iota \mu i ́ \alpha$ (paroimía), que significa lenguaje indirecto, imagen.

${ }^{24}$ El texto griego usa aquí y en la respuesta de los discípulos la palabra $\pi \alpha \rho \rho \eta \sigma i ́ \alpha$ (parresía), que significa franqueza, libertad, confianza.

25 S. SiLva, ¿Por qué murió Jesús? 392.

26 R. Guardini, Der Gegensatz 270-271. 
mediante conceptos y juicios abstractos; solo se los puede contemplar como figuras (Gestalten). La contemplación (Anschauen) consiste en la visión de la figura esencial, en la iluminación del contexto de sentido $\mathrm{y}$, de parte del que contempla, en el ser afectado por el valor de lo que contempla. El proceso se da de tal modo que la parte es comprendida a partir del todo y, viceversa, el todo a partir de cada una de sus partes.

Si esta forma de mirar se abre espontáneamente, queda sin control y muda. Pero es posible llevarla a cabo mediante una técnica lógica, lo que permite expresar el resultado de manera ordenada y responsable. Esta técnica es la dialéctica.

La afirmación directa se puede comparar a una línea recta, que va inmediatamente, sin mediación, al objeto; la dialéctica, en cambio, opera con un haz de afirmaciones, todas ellas referidas unas a otras, de manera que solo en su conjunto abarcan aquello a lo que se refieren. Esta forma de conocimiento es especialmente importante cuando se trata de la existencia humana.

A algo análogo apunta Giuseppe Ruggieri cuando rechaza la idea de poner en la base de la teología sistemática un único concepto fundamental; más aun, rechaza que este pueda ser el de revelación, incluso cuando es comprendida como autocomunicación de Dios. Su argumento es que el dinamismo del acontecimiento cristiano «se deja expresar mejor mediante una pluralidad de imágenes y de conceptos, no subordinados a una idea sistemática, sino relativos al carácter insondable del misterio divino, a la riqueza inagotable de sus manifestaciones y a que se ha hecho cercano al ser humano». Me parece que tiene razón, pero inevitablemente el ser humano tiende a comprender esa riqueza divina y eso lo lleva a algo así como a un concepto fundamental, algo que ordene (provisoria y siempre limitadamente) su comprensión de esa riqueza inagotable. Poco más adelante afirma: «ciertamente es más adecuado el simbolismo bíblico en la variedad de sus elementos» ${ }^{27}$.

27 «(...) si lascia meglio esprimere in una pluralità di immagini e di concetti, non subordinati ad una idea sistematica, ma relativi all'insondabilità del mistero divino, alla ricchezza inesauribili delle sue manifestazioni e del suo farse vicino all'uomo». «(...) certamente è più adeguato il simbolismo biblico nella varietà dei suoi elementi». Ambas citas en G. RugGiERI, La problematica della rivelazione come "concetto fondamentale" del cristianesimo. Associazione Teologica Italiana, La teologia della rivelazione. Atti del III 


\section{Conclusión}

De lo expuesto, me parece que se desprende que el desafío permanente para la teología es incorporar decididamente en todo su quehacer la realidad del Dios que nos ha mostrado Jesús. En particular, si Dios es el Absoluto, no se trata de un absoluto estático, como plenitud del ser, porque Dios es amor, plenitud dinámica de vida, hecha de permanente donación y recepción perijorética del Otro, y -por eso- Trinidad. No se trata tampoco de un absoluto autocontenido, encerrado en sí mismo, en el goce de su propia perfección y plenitud de ser, sino de un absoluto relacional, trinitario (en Sí mismo) y creador (fuera de Sî), pero creador no porque le falte algo y necesite recibirlo de otro, sino por exceso de amor.

Ahora bien, si Dios se ha hecho historia en Jesús de Nazaret, el desafío desborda a la sola teología sistemática y alcanza también a la Iglesia en cuanto es el Cuerpo de Cristo en la historia pospascual. Si la Cabeza se ha hecho historia, el Cuerpo no puede menos de hacerse historia. Para la Iglesia esto implica entrar verdaderamente en la inmensa variedad de culturas y subculturas de la humanidad y en todas las fases de su evolución en el tiempo. Inevitablemente, la Iglesia ha de tener un rostro plural, hecho de las diversas culturas de la humanidad en las que logre hacer pie para vivir en ellas y desde ellas la única fe en Jesús. La pluralidad de rostros de la Iglesia planteará cada vez más -ya está planteando- la pregunta por su unidad. A mi juicio, esta no se logra por la uniformidad -ni siquiera reducida a un mínimo doctrinal, litúrgico y disciplinar- ni por la dependencia administrativa respecto de un centro único, como podría pensarse que es el Papado. La vía para lograr la unidad de una Iglesia plural ya está señalada en el Nuevo Testamento.

En Antioquía ha nacido la primera comunidad cristiana no judía y se ha sentido libre de la Ley. Pero esto ha parecido inaceptable a cristianos del entorno de Santiago en la Iglesia de Jerusalén, y ha estallado el conflicto. Más allá del aspecto jurídico y religioso del problema, creo que lo que está en juego se entiende mejor recurriendo a lo que en la modernidad se ha llamado cultura. Los cristianos de cultura helénica, ¿tienen que hacerse de cultura judía para ser verdadera y plenamente cristianos y, así, salvarse? La respuesta de Pablo es un decidido no, y es la que termina por imponerse en la Iglesia naciente. Se abre así la puerta a la pluralidad de Iglesias

Corso di Aggiornamento, Roma 4-5 gennaio 1993, D. Valentini (a cura di) (Padova 1996) 81-105; las citas en 101. 
cristianas, lo que plantea de inmediato la pregunta por su unidad. La solución la ve Pablo en una doble trascendencia de la Iglesia, que expone con hondura y sencillez cuando relata el fin del conflicto con los judaizantes. Por un lado, los responsables de la Iglesia madre de Jerusalén reconocieron que es el mismo Dios el que actúa en Pedro, para evangelizar a los judíos, y en Pablo, para los no judíos; es decir, reconocieron «la gracia que me había sido concedida» (Gal 2, 9). Por otro, estos mismos responsables pidieron a Pablo y Bernabé «que nos acordáramos de los pobres» (Gal 2, 10) de la Iglesia de Jerusalén. La Iglesia es vivida como una comunión de comunidades diversas, unidas por la común preocupación por los pobres, más que por la centralización del ejercicio de la autoridad. A esta doble trascendencia hay que añadir la hermosa y fundamental afirmación de Pablo VI en la Evangelii Nuntiandi, en la que se basa la libertad para inculturar el Evangelio, desprendido de todo lastre cultural, en cualquier cultura: Jesús mismo es el Evangelio de Dios (EN 7), no un conjunto de formulaciones y ritos. La unidad de la Iglesia no se hace desde dentro de su propia estructura organizacional sino desde fuera: desde Dios, que la envía al mundo; desde Jesús, que es el contenido de lo que ella debe vivir y anunciar; y desde los pobres, predilectos de Dios, en cuyo servicio común la Iglesia plural se hace una. 
Resumen: El artículo parte afirmando el carácter histórico de la teología, que le viene por el hecho de ser obra de seres humanos. Es histórico todo ser que está en devenir, lo que implica estar siendo, en relación con el entorno, desde un centro interior de conciencia y libertad, capaz de decidir. Usando una analogía musical, la teología es histórica no solo porque su intérprete, el ser humano, es histórico, sino también y sobre todo porque su tema lo es: el Dios que se encarna y, así, se hace historia. De aquí los dos desafíos que aborda el artículo: a) ¿Qué hace posible en Dios y en la historia humana que Dios se haga historia, es decir, que pueda devenir-en-interacción-conlos-demás-en-dirección-a-un-porvenir? La respuesta fundamental es, en Dios, que Él es Trinidad, es decir, que "deviene" con otros. Y, en la historia, el acto creador, como un poner al sujeto que puede acoger una autocomunicación de Dios fuera de sí. b) ¿Cómo ha de ser la teología que piense adecuadamente este hacerse historia de Dios y cómo ha de ser el lenguaje en que se exprese esa teología? La teología debe dirigirse a los contemporáneos, porque ellos son los que experimentan el deseo de Dios puesto en ellos por el acto creador, deseo al que la teología aporta la respuesta de la revelación; debe pensar hoy al Dios testimoniado en la Escritura, el que ya se ha hecho historia; y debe buscar no tanto fijar naturalezas cuanto mostrar estructuras del devenir. El lenguaje de la teología no puede ser directo, denotativo, porque a Dios nadie lo ha visto nunca, sino indirecto, connotativo; de aquel se dan dos ejemplos: el lenguaje de Jesús en los evangelios y la propuesta de Guardini de un lenguaje indirecto, como el único capaz de asir lo viviente concreto.

Palabras clave: Encarnación, historia, desafíos de la historicidad, teología, lenguaje teológico, Supra-Devenir de Dios, creación, anhelo de Dios, círculo hermenéutico, denotación, connotación.

Abstract: This article begins by affirming the historical character of theology, which comes from the fact of being the work of human beings. All beings are historic who are in the process of becoming, which implies being, in relation with the environment, from an inner center of consciousness and freedom, capable of deciding. Using a musical analogy, theology is historical not only because its interpreter, the human being, is historical, but also and above all because its subject is; God becomes incarnate, and thus becomes history. Hence the two challenges addressed by the article are: a) What is there in God and in human history that makes it possible for God to become history, that is, that He can become-through-interaction-with-therest-toward-a-future? The fundamental answer is, in God, that $\mathrm{He}$ is the Trinity, that is, that He "becomes" with others, and, in history, is the act of creation, as the placement of the subject who can foster a self-communication with God from the outside. b) How must the theology that properly thinks through God's becoming history be, and how must the language that expresses that theology be? The theology must address contemporaries, because they are the ones that experience God's desire put in them by a creative act, a desire to which the theology gives revelation as the answer. It must think today about the God testified to in the Scripture, He 
368 | Sergio Silva

who has already become history, and must seek not to define natures so much as to show structures of becoming. The language of the theology must not be direct, denotative, because no one has ever seen God, but rather indirect, connotative. There are two examples of this: the language of Jesus in the Gospels and the Guardini's proposal of an indirect language as the only language capable of grasping the living and concrete.

Keywords: Incarnation, history, challenges of historicity, theological language, God's Supra-Becoming, creation, longing for God, hermeneutic circle, denotation, connotation. 